Our Nature (2009) 7:32-38

\title{
Habitat Preference of Auriscalpium vulgare Gray Inhabiting Slash and Burn Affected Khasi Pine Cones of India
}

\author{
P. Das ${ }^{1}$, A. Chettri ${ }^{2}$ and H. Kayang ${ }^{{ }^{*}}$ \\ ${ }^{1}$ Microbial Ecology Laboratory, Department of Botany, North Eastern Hill University, Shillong- 793 022, India \\ ${ }^{2}$ Forest Ecology and Biodiversity Research Laboratory, Department of Botany, North Eastern Hill University, \\ Shillong- 793 022, India \\ *E-mail: hkayang@nehu.ac.in
}

Received: 03.01.2009, Accepted: 28.10.2009

\begin{abstract}
Slash and burn shifting cultivation or jhum is the predominant form of land use pattern in the hilly terain of northeast India. Impact of jhum practice on Auriscalpium vulgare growing on the female Khasi pine cone was studied. The period of mature cone falling proceeds after the slash and burn activity, hence only 1:3 escapes the burning practice. During the assessment, burned and unburned cones were assigned to coarse woody debris (CWD) and classified into three girth classes: small $(\leq 10 \mathrm{~cm})$, intermediate $(>10$ to $\leq 13 \mathrm{~cm})$ and large $(>13 \mathrm{~cm})$. The mean number of basidiocarps in burned cones was significantly higher than unburned ones $(\mathrm{p}<0.00001)$. A significant linear relationship between girth size of burned cones and number of basidiocarps was observed $(r=0.736 ; p<0.01)$. The study reveals that maximum number of fungi thrives on the burned cones (anthropogenically disturbed) of pine and girth size affects the number of basidiocarp.
\end{abstract}

Key words: burned and unburned pine cones; coarse woody debris (CWD); Khasi pine; slash and burn

\section{Introduction}

Slash and burn agriculture is a major land utilization pattern of Northeast India (Ramakrishnan, 1985). Slash and burn are often main features of forest disturbance and reformation in Northeast India (Deka and Mishra, 1983). Their role in changing floristic composition is extensively studied (Cammeraat and Imeson, 1999). The mechanism of fire can be separated into a direct and several indirect effects on soil microbial communities. In addition, soil microbial population as well as enzyme activity decreased in slash and burn soil system (Dkhar and Mishra, 1983). Studies related to the effect on the community of macrofungi by slash and burns are meager (Visser, 1995; Dahlberg, 2002).

Auriscalpium vulgare is a basidiomycetous fungus, dark brown, hispid, and leatherymembranaceous. Pileus reniform, singly or in groups of two or three carpophores on buried conifer cones (Hall and Stuntz, 1971). The species is widely distributed throughout the coniferous region of United States, Canada and Europe (Smith, 1949). There are few reports from Asia (Geesteranus, 1971). More than 27,000 species of fungi were recorded in India. Approximately 850 species of mushrooms are recorded from India (Manoharachary et al., 2005). 
In the present investigation, we examine the occurrence of Auriscalpium vulgare in the slash and burn affected cones of Khasi pine. Khasi pine (Pinus kesiya Royle ex Gordon) is a subtropical tree found in the Khasi hills of Meghalaya, India. The female cones are ovoid, $5-9 \mathrm{~cm}$ long, often curved downwards, sometimes slightly distorted. The scales have transverse and longitudinal ridges across the middle of the scale surface (Conifer Specialist Group, 1998). Our aim is to determine whether there is any variation in the population of fungi and to establish the relationship of cone size and number of basidiocarp in burned cones (anthropogenically disturbed) and the unburned cones.

\section{Methodology}

\section{Site description}

The survey was conducted in the pine forest located in Shillong, India situated in the North eastern part of the country $\left(25^{\circ} 36.735^{\prime} \mathrm{N}, 091^{\circ} 53.880^{\prime} \mathrm{E}\right)$. It covers an area of 485.64 ha with slope of $18-30^{\circ}$ and altitude of $1537 \mathrm{~m}$. msl. The selected site for sampling was $600 \mathrm{~m}^{2}$. The data of average monthly rainfall, temperature and relative humidity were collected from the nearest meteorological station, Shillong, India (Figure 1) situated three kilometer away from the study site. The floristic aspect of the area studied is sub-tropical forest dominated by pine and the undergrowth is covered by herbaceous vegetation (Haridasan and Rao, 1985). The collection and observation was carried out during the month of July, 2007.

\section{Identification}

Colour, locality and characteristics of habitat, etc. were noted during the collection. The photography was done in situ and for the collected specimens in the laboratory. 12 fresh basidiocarps were collected from the site for macroscopic observation and for herbaria preparation. Samples were then dried and preserved in sterilized brown paper bags. In the laboratory, microscopic features, especially the spore properties of macro fungi species were observed by using Leitz Wetzlar Germany 513467.

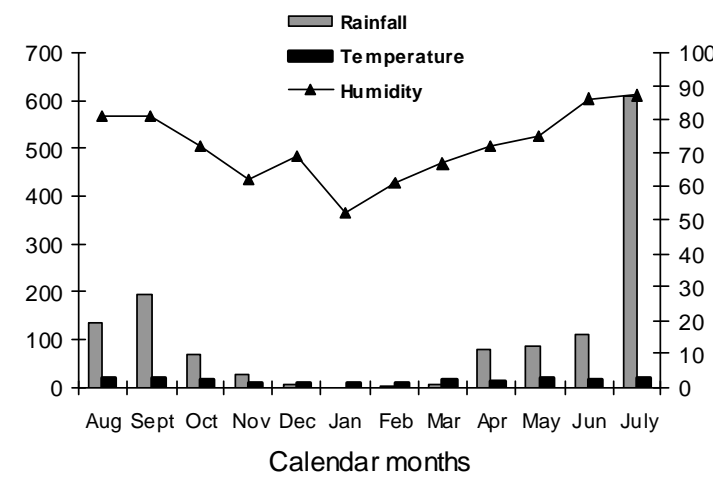

Figure 1. Monthly rainfall $(\mathrm{mm})$, temperature $\left({ }^{\circ} \mathrm{C}\right)$ and humidity (\%) between August, 2006 to july, 2007.

The identification of the taxa was carried out with the aid of descriptions (Smith, 1949; Geesteranus, 1971). Author and taxa were specified according to an amended CABI Bioscience electronic version (http://www.speciesfungorum.org/Authors of Fungal Names.htm). The voucher specimens were deposited in the Fungi Herbarium collection, Microbial Ecology Laboratory, North Eastern Hill University, India.

\section{Pine cone and basidiocarp measurement}

The fallen cones were assigned to coarse woody debris (CWD). The random sampling was applied to CWD in the study. The basidiocarps in CWD were selectively sampled in the forest to obtain representative samples by laying 55 quadrat 
of $1 \mathrm{~m}^{2}$ measured with tape. The data were recorded as presence or absence of a species on CWD. Only CWD exceeding $8 \mathrm{~cm}$ girth was considered in the study with diameter > $2.5 \mathrm{~cm}$ (Harmon et al., 1986). Girth size was measured at the middle and at the two extreme ends of the cone and mean was considered. In addition numbers of burned and unburned cones were recorded. Attempt was made to estimate the number of basidiocarps in a cone. The size of the stipe and the pileus was measured with the help of scale. For moisture content (\%), $10 \mathrm{~g}$ sub sample of cone scale was oven dried and weight was determined.

\section{Statistical analysis}

Quantitative analyses are based on CDW and were classified in three girth classes: small $(\leq 10 \mathrm{~cm})$, intermediate $(>10$ to $\leq 13$ $\mathrm{cm})$ and large $(>13 \mathrm{~cm}$ ) (girth ranged between 8.4 and $15.6 \mathrm{~cm}$ ). The fungi on burned cones explored were frequent (occurring on more than $8 \%$ of all cones) and on unburned cones (occurring in more than $1 \%$ ). The population of observations on cone girth was tested for normality by plotting observed and expected frequency distributions followed by KolmogorovSmirnov (K-S) test.

Two tails student t-test was performed with the number of burned and unburned cones and species population difference in the number of burned and unburned cones. Spearman's rank correlation coefficient (Zar, 1974) between cone girth and basidiocarps was also performed.

\section{Results}

\section{Substrate characteristics}

The study revealed that the fallen female cones of pine were affected by the annual slash and burning, the macrofungi occupied two types of cones i.e., burned and unburned cones (Figure 2). The cones were found in several states viz. buried, fully burned and incomplete burned and unburned. There were statistical difference in the number of burned and unburned cones $(t=8.84, d f=108, p<0.0000001)$.
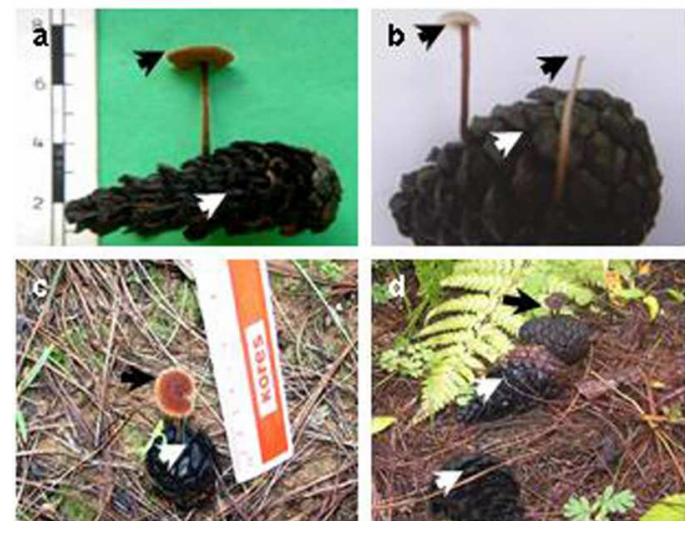

Figure 2. Khasi pine cones (white arrows) inhabited by $A$. vulgare (black arrows) in (a) burned cone (b) unburned cone (c) basidiocarp in slightly affected burned cone in the pine forest (d) basidiocarp in unburned cone and two burned cones without the fungi.

The expected frequency distribution of basidiocarps was normal in the burned and unburned cones (Figure 3). The basidiocarps growing in cones observed during the survey in the girth class of 8-9 $\mathrm{cm}$ to $15-16$ $\mathrm{cm}$ (Table 1). Girth of all burned cones ranged between $8.4 \mathrm{~cm}$ and $15.6 \mathrm{~cm}$ and averaged $11.53 \pm 0.2 \mathrm{~cm}$. The basidiocarps observed in unburned cones size ranged between 9.2 and $14.9 \mathrm{~cm}$ and averaged around $11.5 \pm 0.67 \mathrm{~cm}$. The intermediate diameter classes were utilized by the species in burned cones. The least number of basidiocarps were noticed in the large girth class $14-15 \mathrm{~cm}$ and most in the intermediate 
class of $11-12 \mathrm{~cm}$. The order of maximum number of burned cones encountered in the girth class of $11-12>12-13>10-11>13-$ $14>8-9>9-10>15-16>14-15$.

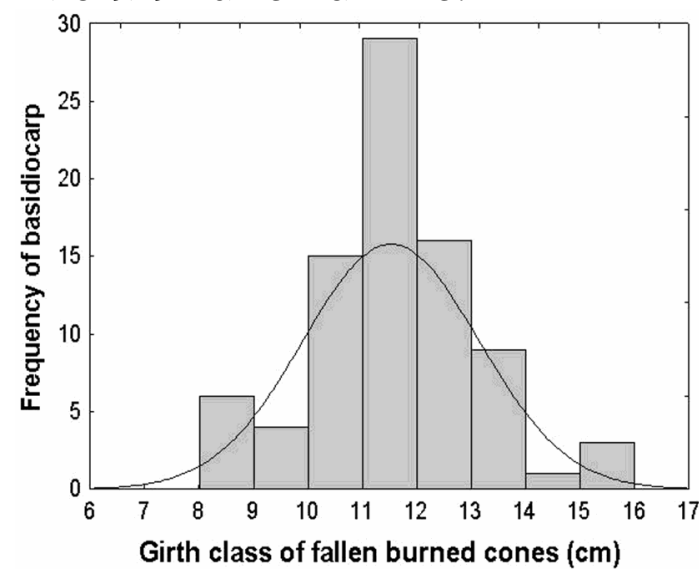

Figure 3. Frequency distribution of A. vulgare in burned cones. The observed distribution (bar) was fitted to an expected normal distribution (curve). Skewness was 0.366 , kurtosis was 0.441 and $\mathrm{K}-\mathrm{S}$ test yielded $\mathrm{d}=0.081$ at $\mathrm{p}>0.20$.

Table 1. Basidiocarps in different girth size of cones.

\begin{tabular}{ccc}
\hline $\begin{array}{l}\text { Girth size } \\
\text { (class } \\
\text { interval) }\end{array}$ & $\begin{array}{l}\text { Basidiocarps in } \\
\text { burn cone }\end{array}$ & $\begin{array}{l}\text { Basidiocarps } \\
\text { in unburn } \\
\text { cone }\end{array}$ \\
\hline $8-9$ & 6 & 0 \\
$9-10$ & 4 & 5 \\
$10-11$ & 15 & 1 \\
$11-12$ & 29 & 1 \\
$12-13$ & 16 & 1 \\
$13-14$ & 9 & 8 \\
$14-15$ & 1 & 4 \\
$15-16$ & 3 & 0 \\
\hline
\end{tabular}

The expected frequency distribution of basidiocarps was not normal in the unburned cones. The unburned cones in the girth class interval of $9-10 \mathrm{~cm}$ to $14-15 \mathrm{~cm}$ exhibiting irregular distribution. The least number of basidiocarps were noticed in the intermediate girth class $10-13 \mathrm{~cm}$ and most in the higher class interval of $13-14 \mathrm{~cm}$. The order of highest number was found in the girth class of 13-14>9-10>14-15>10 $1=11-12=12-13$ in unburned cones. The maximum number of basidiocarps in individual unburned cone is 7 and 4 numbers of basidiocarps in each burned cone. The number of basidiocarps varies from 1-4 in burned cone and 1-7 in unburned cones.

\section{Moisture gradient}

The study of different states of fallen cones i.e., basidiocarps in buried burned, burned and unburned cones; without basidiocarps in burned and unburned cones exhibit a gradient of moisture content $(\%)$ in the substrata (Figure 4). The maximum amounts of moisture were found in the cones inhabited by basidiocarps. The basidiocarps in the buried cones shows the utmost moisture content $(79.2 \%)$ followed by burned and unburned cones bearing basidiocarps. There was steep fall in moisture content from buried cones to burned having basidiocarps as depicted in the graph. From this point, fall in moisture content decreases from burned cones with basidiocarps to unburned cones without basidiocarps. The maximum difference of moisture was analyzed in the buried and burned cones possessing basidiocarps. The cones without the fungus exhibit the minimum amount of moisture content where the unburned ones possess the lowest moisture content (44.2\%).

\section{Basidiocarps population and variation in cone types}

The survey revealed 103 basidiocarps; the 83 fungi inhabited in the burned cones and only averaging 12 in the unburned cones. The number of basidiocarps in burned and 
P. Das, A. Chettri and H. Kayang / Our Nature (2009) 7: 32-38

Table 2. Number of cone, basidiocarp and basidiocarp size

\begin{tabular}{lllllllllc}
\hline \multirow{2}{*}{ Cone types } & \multirow{2}{*}{ *Cone } & \multirow{2}{*}{ *Basidiocarp } & \multicolumn{3}{c}{ Basidiocarp size $(\mathrm{cm})$} & \multicolumn{5}{c}{ No. of basidiocarp in individual cone (\%) } \\
\cline { 4 - 9 } & & Stipe & Pileus & 1 & 2 & 3 & 4 & 5 \\
\hline Burned & 10.47 & $1.51 \pm 0.15$ & 2.6 & 1.18 & 67.25 & 24.14 & 6.89 & 1.72 & 0.0 \\
& \pm 0.77 & & \pm 0.11 & \pm 0.06 & & & & & \\
Unburned & 3.41 & $0.36 \pm 0.14$ & 2.44 & 1.06 & 75.00 & 16.66 & 0.00 & 0.00 & 8.34 \\
& \pm 0.24 & & \pm 0.24 & \pm 0.18 & & & & & \\
\hline
\end{tabular}

*Mean $( \pm$ SE); $p<0.05$

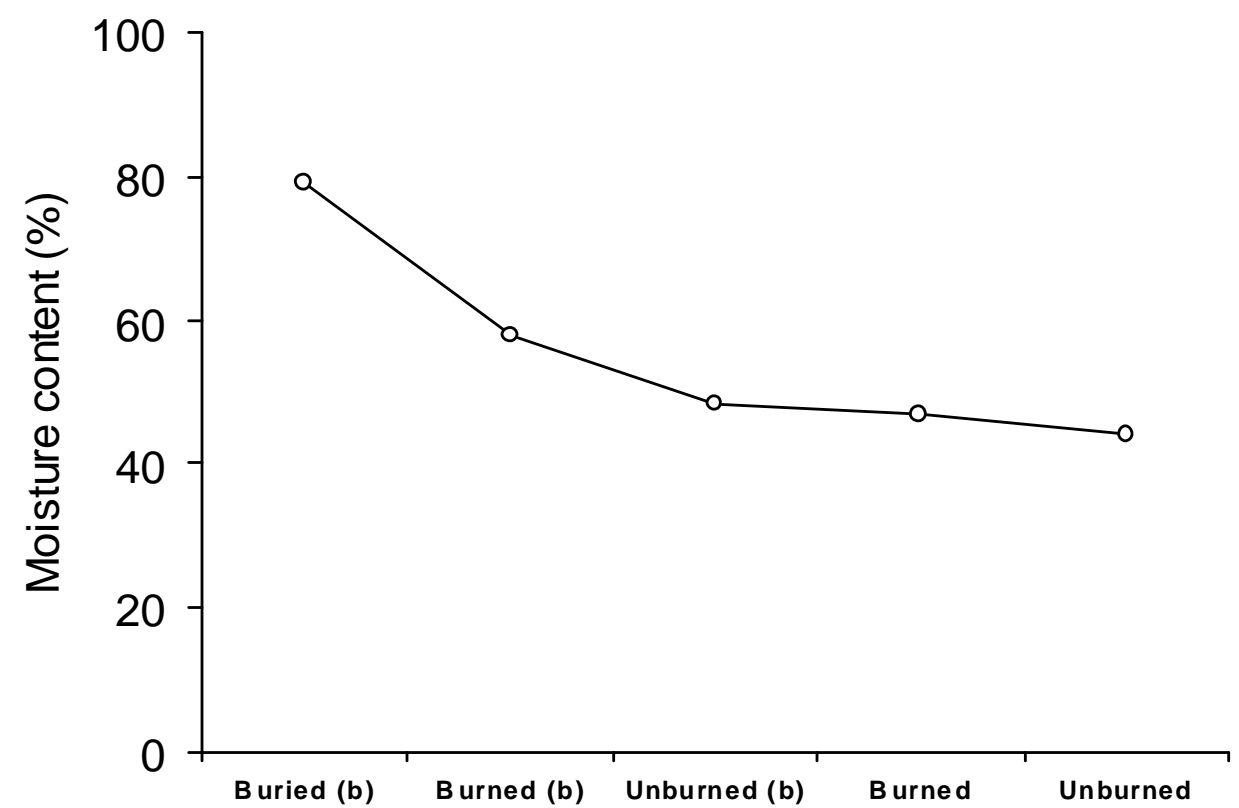

Figure 4. Moisture content (\%) of pine cones where (b) are all cones with basidiocarp growing in different conditions.

unburned cones were statistically significant $(\mathrm{t}=4.77, \mathrm{df}=54, \mathrm{p}<0.00001)$. The stipe size of basidiocarps in burned cone ranges between $0.7-4.7 \mathrm{~cm}$ and in unburned cones $0.9-4.2 \mathrm{~cm}$. The pileus size of basidiocarps in burned cone was $0.6-2.3 \mathrm{~cm}$ and in unburned cones $0.5-1.5 \mathrm{~cm}$ (Table 2).

Analyzing the relationships between girth size of burned and unburned cones and number of basidiocarps revealed a positive linear correlation. In general, the interrelation between the girth and the number of basidiocarps in burned and unburned cones was significantly correlated. The two variables i.e., between girth size of unburned cone and number of basidiocarps significantly different having the value $(r=0.736, n=64, p<0.01)$. However, the relationships between girth size of burned cones and number of basidiocarps revealed insignificant correlation.

\section{Discussion}

Results reveal that maximum number of cones in pine forest is affected by tradition 
of slash and burn practices. The slash and burn generally involves slashing the herbs, shrubs and lower branches of the thinly distributed pine trees in December and burning in the following March (Ramakrishnan and Mishra, 1981). During this dry windy month fallen cones $(75 \%)$ of previous year get affected from fire. The seed dispersal and mature cone fall takes place in May-June (Singh, 2002), hence these unaffected cones are less $(25 \%)$ and escape the burning practice. Thus, there is significant difference between basidiocarps in burned cones and unburned cones. Therefore, typical selection of habitat by macro fungi on burned pine cones was high.

The impact of fire on biological properties of soil depends strictly on soil moisture (Joshi et al., 1991) which was only determined in case of cones. The fungi were encountered in the cones with maximum amount of moisture. The cones without the basidiocarps were harboring the least amount of moisture. The maximum burned cones with basidiocarps were found to be half and slightly burned cones which fall in the intermediate size of the cones and eventually substrate utilization was more. The varying numbers of basidiocarps is 1-7, maximum number occurred only in one cone which may not be convincing that disturbance is affecting the number of fungi. The burned cones may possibly promote the better growth of this fungus. The intensity of the fire needs to be ascertained as low and moderate amount of fire which may have some role to play. There is report of a stimulatory effect of low and moderate severity fires on fungi (Certini, 2005).

The correlation coefficient is statistically significant between girth size of unburned cones and number of basidiocarps which could be applied to the burn effect which reduces cones to disproportionate size in case of burned cones. Moreover, the basidiocarps were found to emerge beneath the cone scales and burning leads to asymmetrical and loss of cone scales. Hence, unburned cones are intact providing maximum substrate and may be favorable for higher number of basidiocarps to grow.

The clear cut generalization emerged, which could be applicable for all the data that the maximum number of macrofungi inhabiting the burned cone although, anthropogenic disturbances which reflects in the form of burned cones was well established and the fungus was growing very well in these conditions. Moreover, girth size of cones affect the numbers of fungi in cones, especially the intact unburned cones relation with girth size indicate that number of basidiocarps increases with the increase in girth size.

\section{Acknowledgements}

The authors are thankful to the Head, Department of Botany for providing laboratory facilities. The first author is grateful to the University Grant Commission, New Delhi for financial support in the form of senior research fellowship. The second author is also grateful to University Grant Commission for meritorious scholarship.

\section{References}

Cammeraat L.H. and A.C. Imeson 1999. The evolution and significance of soil-vegetation patterns following land abandonment and fire in Spain. The significance of soil, water and landscape processes in banded vegetation patterning. Catena 37: 107-127.

Certini, G. 2005. Effects of fire on properties of forests: a review. Oecologia 143: 1-10.

Conifer Specialist Group 1998. Pinus kesiya In IUCN 2006. IUCN Red List of Threatened Species. www.iucnredlist.org. 
P. Das, A. Chettri and H. Kayang / Our Nature (2009) 7: 32-38

Dahlberg, A. 2002: Effects of fire on ectomycorrhizal fungi in Fennoscandian boreal forests. Silva Fennica 36: 69-80.

Deka, H.K., and R.R. Mishra 1983. The effect of slash burning on soil micro flora. Plant and soil 73: 167175.

Dkhar, M.S. and R.R. Mishra 1983. Dehydrogenase and urease activities of maize (Zea mays L.) field soils. Plant and soil 70:327-333.

Geesteranus, R.A.M. 1971. Hydnaceous fungi of the eastern old world, North Holland Publishing Company, Amsterdam. pp. 20-21

Hall, D. and D.E. Stuntz 1971. Pileate Hydnaceae of the Puget Sound Area. I. White-Spored Genera: Auriscalpium, Hericium, Dentinum and Phellodon. Mycologia 63: 1099-1128.

Haridasan, K. and R.R. Rao 1985. Forest Flora of Meghalaya, Bishen Singh Mahendra Pal Singh, Dehradun, India.

Harmon M.E., J.F. Franklin, F.J. Swanson, P. Sollins, S.V. Gregory, J.D. Lattin, N.H. Anderson, S.P. Cline, N.G. Aumen, J.R. Sedell, G.W. Lienkaemper, K. Cromack and K.W. Cummins 1986. Ecology of coarse woody debris in temperate ecosystems. Advances in Ecological Research 15: 133-302.

Joshi, S.R., G.D. Sharma and R.R. Mishra 1991. Effect of disturbance on microbial population and their activities in forests soils at higher altitudes of
Meghalaya. In High Altitudes of Himalaya (Biogeography, Ecology and Conservation) (Eds. P.S. P angtey and R.S. Rawal). Gyanodaya Prakashan, Nainital. pp. 298-309.

Manoharachary, C., K. Sridhar, R. Singh, A. Adholeya, T.S. Suryanarayanan, S. Rawat and B.N Johri 2005. Fungal biodiversity: Distribution, conservation and prospecting of fungi from India. Current Science 89: 58-71.

Ramakhrishnan, P.S. and B.K. Mishra 1981. Population dynamics of Eupatorium adenophorum Spreng. During secondary succession after slash and burn agriculture (jhum) in north eastern India. Weed Research 22: 77-84.

Ramakrishnan, P.S. 1985. Tribal man in the humid tropics of the north-eastern India. Man in India 65: $1-32$.

Singh, N.D. 2002. Studies on the environmental information in tree rings of some tree species growing in North East India. Department of Botany, North Eastern Hill University, India. (Ph.D. Thesis)

Smith, A.H. 1949. Mushrooms in their natural habitat. Hafner press, New York, pp. 226-227

Visser, S. 1995. Ectomycorrhizal fungal succession in jack pine stands following wildfire. New Phytologist 129: 389-401.

Zar, J.H. 1974. Biostatistical analysis. Prentice Hall, INC., Englewood Cliffs, New Jersey. 